\title{
Study of Portal Vein Diameter and Spleen Size by Ultrasonography and Their Association with Gastro-esophageal Varices
}

\author{
Bhattarai $S^{1}$, Gyawali $\mathbf{M}^{\mathbf{2}}$, Dewan $\mathbf{K R}^{1}$, Shrestha $\mathbf{G}^{\mathbf{1}}$, Patowary $\mathbf{B S}^{\mathbf{1}}$, \\ Sharma $\mathbf{P}^{2}$ \\ ${ }^{1}$ Department of Gastromedicine, CMS Teaching Hospital, Chitwan, Nepal, \\ ${ }^{2}$ Department of Radiodiagnosis, Manipal Teaching Hospital, Pokhara, Nepal \\ Correspondence to: Dr Subash Bhattarai; Email: kiwisubash@yahoo.com
}

\begin{abstract}
Introduction: Upper Gastro-intestinal endoscopy is considered the best screening tool for varices in cirrhotic patients. It is still an expensive, invasive tool, has poor compliance and not routinely available in every hospitals in Nepal. This study was undertaken to establish the role of portal vein diameter and spleen size by ultrasonography in predicting gastroesophageal varices.
\end{abstract}

Method: One hundred and fifty patients with clinical features, laboratory and sonological findings suggestive of cirrhosis of liver and endoscopic evidence of portal hypertension were included in the study. Ultrasonography assessments of portal vein diameter and spleen size alongside endoscopy for detection of varices were done.

Result: Average portal vein diameter of patients without gastro-esophageal varices was $10.800 \pm 1.1402 \mathrm{~mm}$, while it was $13.731 \pm 1.061 \mathrm{~mm}$ in patients with varices $(\mathrm{p}<0.001)$. Average spleen size of patients without varices was $12.67 \pm 2.35 \mathrm{~cm}$ and with varices was $15.367 \pm 1.210 \mathrm{~cm}(\mathrm{p}<0.001)$. There was $92.72 \%$ sensitivity and $90 \%$ specificity for prediction for presence of esophageal varices when the cutoff value for portal vein diameter was $12.25 \mathrm{~mm}$. There was $94.5 \%$ sensitivity and $75 \%$ specificity for prediction for presence of esophageal varices when the cutoff value for spleen size was $13.9 \mathrm{~cm}$.

Conclusion: Ultrasonography of portal vein diameter and spleen size is a reliable non invasive tool in predicting the presence of gastro-esophageal varices in patients with liver cirrhosis. With increase in portal vein diameter and spleen size, risk of formation of gastroesophageal varices also increases and positive correlations exist between them.

Keywords: Cirrhosis of liver; Gastro-esophageal varices; Portal vein diameter; Spleen size; Ultrasonography. 


\section{INTRODUCTION}

One of the major causes of morbidity and mortality in Nepal is liver cirrhosis. National data on the exact burden of the disease is lacking. Alcohol consumption is the major cause of cirrhosis in Nepal. Cirrhosis of liver refers to a progressive, diffuse, fibrosing, nodular condition that disrupts the entire normal architecture of the liver. The majority of cases are attributed to excessive alcohol consumption, viral hepatitis, or nonalcoholic fatty liver disease worldwide ${ }^{1}$.

Portal hypertension is a significant complicating feature of cirrhosis and is responsible for the development of ascites, splenomegaly and gastro-esophageal varices. Bleeding from esophageal varices is the most serious and an immediate lifethreatening complication ${ }^{2-4}$.

Various studies suggest the prevalence of gastro-esophageal varices is approximately about $50-60 \%{ }^{5}$. The presence of gastroesophageal varices is considered a prognostic indicator and a factor affecting increased mortality. There is around 20$30 \%$ mortality rate associated with each episode of bleeding. Incidence of first variceal hemorrhage ranges from 20 to $30 \%$ within 2 years. The rate of early rebleeding is related to an increased rate of mortality $^{6,7}$.

Prevention of variceal bleeding by pharmacological interventions using nonselective beta blockers and prophylactic endoscopy band ligation are recommended. Upper Gastrointestinal endoscopy is considered the best screening tool for varices in cirrhotic patients and to diagnose those at risk of bleeding. Repeated endoscopic examinations and surveillance are recommended in cirrhotic patients with and without gastroesophageal varices. Despite the advantages of endoscopy, it is still expensive, invasive method, has poor compliance and not routinely available in every hospitals of Nepal.

Ultrasound is a non invasive tool with high patients compliance and available in all hospitals within the country. Ultrasonography of the abdomen can be used for assessment of liver, spleen size, ascites and portal system ${ }^{8}$. Various studies, have demonstrated the relationship between portal vein diameter, spleen size and the presence of esophageal varices.

\section{METHODS AND METHODOLOGY}

The observational, cross-sectional, hospital based study was carried out in Department of Medical Gastroenterology at College of Medical Sciences Teaching Hospital Nepal from Jan 2013 to Dec 2013. Either previously diagnosed or newly diagnosed cases attending outdoor and/or admitted in ward with clinical features, laboratory and sonological findings suggestive of cirrhosis of liver and assessed according to Child-Turcotte-Pugh (CTP) score along with sonological and/or endoscopic evidence of portal hypertension were included in the study.

The following cases with portal hypertension were excluded from the study:

1. Cirrhosis with hepatic encephalopathy III / IV. 
2. Other cases with portal hypertension, i.e., non cirrhotic portal fibrosis, Budd-Chiari syndrome, extra hepatic portal venous obstruction.

3. Critically ill patients, cirrhotic patients with end stage renal failure, hepatocellular carcinoma and those who fail to give consent.

One hundred and fifty cases of cirrhosis of liver were enrolled for the study. A detailed history, general physical examination and clinical examination of the abdomen were carried out. Basic laboratory investigations like complete blood count including platelets count, urine routine and microscopy, random blood sugar alongside tests for liver function test, prothrombin time / international normalized ratio (PT / INR), coagulation profile and others were done.

All subjects were studied in the morning, after an overnight fast. A complete study of liver, spleen, portal, and splanchnic veins by Doppler ultrasonography (TOSHIBA XARIO model SSA-660A ultrasound system) capable of B-mode imaging using a $3.5 \mathrm{MHz}$ curved array transducer was performed by consultant radiologist. Spleen size and portal vein diameter were measured by placing the patient in supine position during full inspiration. The average adult spleen measures $12 \mathrm{~cm}$ in length. The spleen can be more echogenic when it enlarges. A maximum cephalo-caudal measurement of more than $13 \mathrm{~cm}$ indicates enlargement ${ }^{9}$. In normal individuals, the portal vein diameter does not exceed $13 \mathrm{~mm}$ in quiet respiration and is measured where the portal vein crosses anterior to the IVC. Splenomegaly and portal vein enlargement commonly accompanies portal hypertension ${ }^{10,11}$.

Each patient underwent endoscopic investigation by standard flexible gastro duodenal endoscope (PENTAX EPK 700, PENTAX JAPAN Inc) and diagnostic findings were documented. Varices were classified as small ( $\leq 5 \mathrm{~mm}$ diameter) or large ( $>5 \mathrm{~mm}$ diameter) when assessed with full insufflations ${ }^{7}$.

\section{Statistical Analysis}

Data were collected on a structured Performa covering the relevant subjects of the study. Data entry was done in Statistical Packages for the Social Sciences version 20. All categorical data were expressed in percent and absolute number. All numerical continuous data were expressed in mean \pm SD. The data analysis was done using Statistical Packages for the Social Sciences (SPSS) version 20. Chi squared test was used to test for significant difference of proportions (categorical data) and independent $\mathrm{t}$ - test and analysis of variance (ANOVA with Tukey post hoc) were employed to test for significant difference of means (continuous data). Pearson correlation was used to see the association between portal vein diameter and spleen size. Additionally, Receiver Operating Characteristic (ROC) curves for portal vein diameter and spleen size to predict the presence of varices were constructed. Further analyses were performed to estimate the best cut off points for portal vein diameter and spleen size with sensitivities and specificities at those points. All tests were analyzed with a $95 \%$ confidence interval and a $P$ value of $<0.05$ was considered significant. 


\section{RESULTS}

A total of 150 patients with cirrhosis; 117 male $(78 \%)$, and 33 female (22\%) were enrolled in the study. Mean age of the study group was 53.8 years; range 27 - 85 years. Chronic alcohol consumption accounted $120(80 \%)$ of total cases. Twenty cases $(13.3 \%)$ of cases were chronic hepatitis B. 5 cases $(3.3 \%)$ were diagnosed with chronic hepatitis $\mathrm{B}$ and rest
$5(3.3 \%)$ were classified as cryptogenic. Esophageal varices developed in $110(73.4$ $\%)$ patients. Twenty eight patients $(18.7 \%)$ had low-grade and 82 patients $(54.7 \%)$ had high-grade varices. The high prevalence of esophageal varices on endoscopy is probably due to the late presentation of patients. No sex difference in presence of esophageal varices was present in chronic liver disease patients.

All cirrhotic subjects were classified according to Child-Turcotte-Pugh (CTP) score as in Table1. Majority of cases with varices were of Class C. As shown in the table 1, no association was observed between CTP classes and variceal grading. (Chi sq. test; statistic = $7.013 ; \mathrm{df}=4 ; \mathrm{p}=0.135$ )

Table 1: CTP classes and distribution of cases.

\begin{tabular}{|c|c|c|c|c|c|}
\hline \multicolumn{2}{|c|}{} & \multicolumn{3}{|c|}{ CTP } & \multirow{2}{*}{ Total } \\
\cline { 3 - 6 } & Class A & Class B & Class C & \\
\hline \multirow{3}{*}{ Esophageal Varices } & No Varix & 1 & 15 & 24 & $\mathbf{4 0}$ \\
\cline { 2 - 6 } & Small Varices & 0 & 8 & 20 & $\mathbf{2 8}$ \\
\cline { 2 - 6 } & Large Varices & 0 & 17 & 65 & $\mathbf{8 2}$ \\
\hline \multicolumn{2}{|c|}{ Total } & $\mathbf{1}$ & $\mathbf{4 0}$ & $\mathbf{1 0 9}$ & $\mathbf{1 5 0}$ \\
\hline \multicolumn{2}{|c|}{ Chi sq. test statistic $=7.013 ; \mathrm{df}=4 ; \mathrm{p}=0.135$} \\
\end{tabular}

Average portal vein diameter (PVD) of patients without gastro-esophageal varices was $10.800 \pm 1.1402 \mathrm{~mm}$, while it was $13.731 \pm 1.061 \mathrm{~mm}$ in patients with varices $(\mathrm{t}=14.658 ; \mathrm{p}<0.001)$. Moreover, patients with small varices had PVD of $12.650 \pm 0.7471 \mathrm{~mm}$ and those with large varices had $14.100 \pm 0.8883 \mathrm{~mm}(\mathrm{t}=7.75$; $\mathrm{p}<0.001)$. This difference was also statistically significant.
Analysis of variant (ANOVA) result showed that the mean PVD differed significantly amongst the three groups as shown in table 2. Post hoc (Tukey) analysis showed that the mean PVD of individuals with no varix differed significantly with the mean PVD of those with either small or large varices. Additionally, mean PVD of individuals with large varices was significantly greater than those with small varices. 
Table 2: Statistical correlation between portal vein diameter and varices.

\begin{tabular}{|c|c|c|c|c|c|}
\hline & & & & ANC & $\overline{\text { JVA }}$ \\
\hline VARICES & $\mathbf{N}$ & Mean of PVD $(\mathrm{mm})$ & std. Deviation (mm) & F Value & P value \\
\hline No Varix & 40 & 10.800 & 1.1402 & \multirow{3}{*}{167.67} & \multirow{3}{*}{$<0.001$} \\
\hline Small Varices & 28 & 12.650 & 0.7471 & & \\
\hline Large Varices & 82 & 14.100 & 0.8883 & & \\
\hline
\end{tabular}

Average spleen size of patients without varices was $12.67 \pm 2.35 \mathrm{~cm}$ and with varices was $15.367 \pm 1.210 \mathrm{~cm}$. This difference was statistically significant $(\mathrm{t}=$ 9.168; $\mathrm{p}<0.001)$. Patients with small varices had $14.98 \pm 1.55 \mathrm{~cm}$ and those with large varices had $15.50 \pm 1.04 \mathrm{~cm}$. In this case, however, the difference was marginally significant $(\mathrm{p}=0.048)$.

Analysis of variants (ANOVA), to compare the mean of spleen size between the three groups as in table 3 showed that individuals with either small or large varices had statistically significant greater spleen size than those with no varices. However, no such difference was observed between those with small and large varices. This simply implies that increase in spleen size predicts the presence of varices but not the size of the varices.

Pearson correlation between portal vein diameter and spleen size showed that they had significant positive association (correlation coefficient $=0.52 ; \mathrm{p}<0.005$ ).

$\underline{\text { Table 3: Statistical correlation between spleen size and varices. }}$

\begin{tabular}{|c|c|c|c|c|c|}
\hline \multirow{2}{*}{ VARICES } & \multirow{2}{*}{$\mathbf{N}$} & \multirow{2}{*}{ Mean of spleen size $(\mathrm{cm})$} & \multirow{2}{*}{ Std. Deviation $(\mathrm{cm})$} & \multicolumn{2}{|c|}{ ANOVA } \\
\hline & & & & F Value & P value \\
\hline No Varix & 40 & 12.67 & 2.35 & \multirow{3}{*}{43.50} & \multirow{3}{*}{$<0.001$} \\
\hline Small Varices & 28 & 14.98 & 1.55 & & \\
\hline Large Varices & 82 & 15.50 & 1.04 & & \\
\hline
\end{tabular}

Receiver operating characteristic (ROC) curve of portal vein diameter and spleen size when plotted showed that both were significant predictors for the presence of varices. However, the portal vein diameter was stronger predictor (AUC - PVD = $0.956 ; \mathrm{p}<0.001$ vs. AUC - spleen size $=$ $0.878 ; \mathrm{p}<0.001$ ) as in figure 1 . There was $92.72 \%$ sensitivity and $90 \%$ specificity for prediction for presence of esophageal varices when the cutoff value (by ROC curve analysis) for portal vein diameter was $12.25 \mathrm{~mm}$. There was $94.5 \%$ sensitivity and $75 \%$ specificity for prediction for presence of esophageal varices when the cutoff value (by ROC curve analysis) of spleen size for was 13.9 $\mathrm{cm}$. 


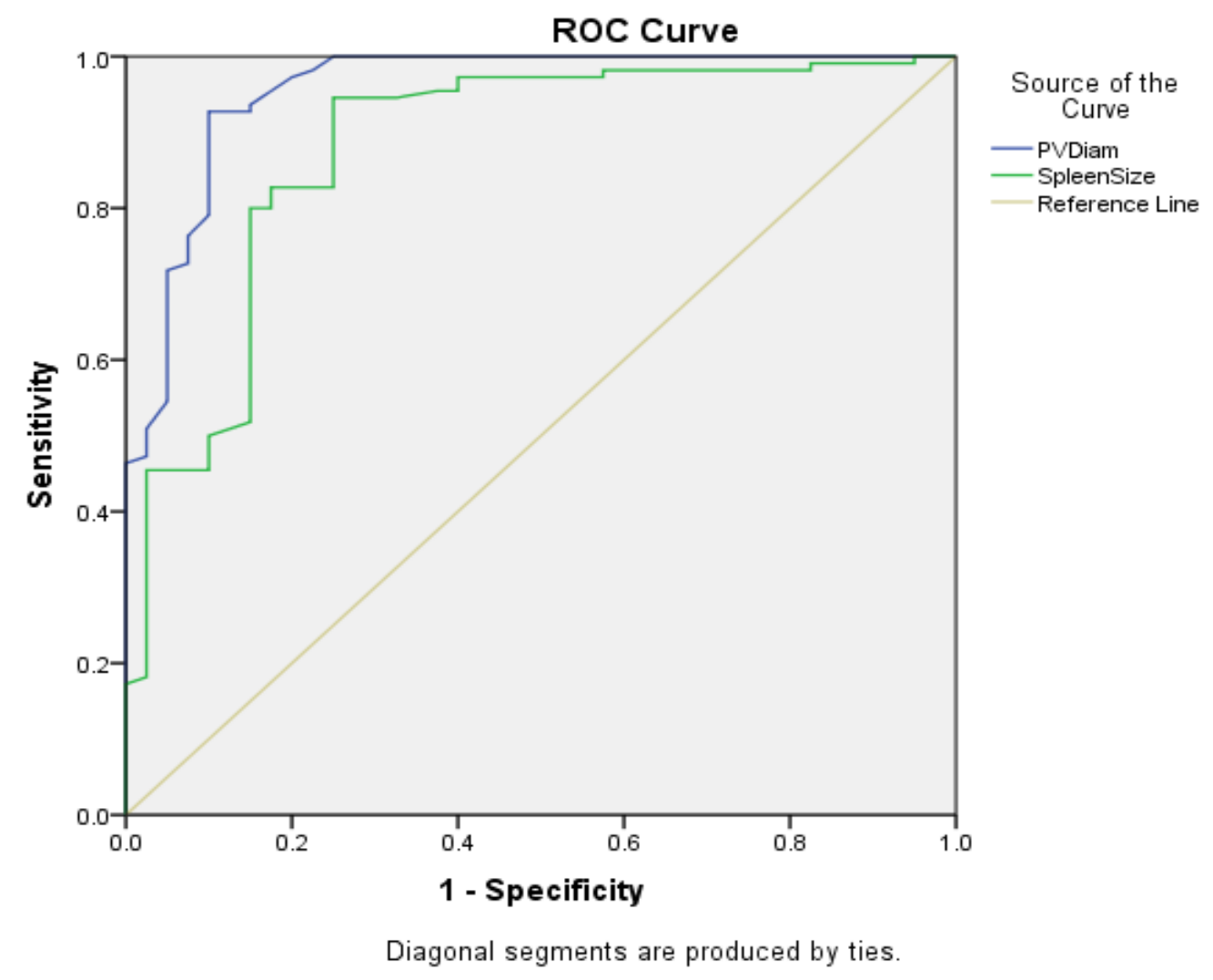

Figure 1: Sensitivity and specificity of portal vein diameter and spleen size for predicting varices (ROC curve analysis)

\section{DISCUSSION}

In developing countries like Nepal where people lack education, adequate knowledge and have poor access to health care facilities, chronic liver diseases remain undiagnosed. People usually present to the hospitals in a late, decompensated state. Endoscopy facilities and specialist are few in the rural areas and villages in Nepal. An alternative non invasive ultrasound is cheap and available in almost all health care centers in villages and remote areas of the country. Assessment of liver and portal hypertension can be carried out in patients with cirrhosis of liver using ultrasonography of the abdomen. This study was undertaken to establish the role of portal vein diameter and spleen size by ultrasonography in predicting gastroesophageal varices and to study the correlation between them, if any exist.

Various studies, have demonstrated the relationship between portal vein diameter, spleen size and the presence of esophageal varices. 150 cirrhotic patients (male $78 \%$; female $22 \%$ ) with mean age of 53.77 years (median age of 54 years; range 27-85 years) were enrolled in the study. In an Indian study by Mandal et al. ${ }^{12}$, eighty two patients were selected out of which 56 were males and median age of the study population was 40 years, range being 19 to 64 years. In another Indian study of 101 patients (median age 45 years) by Sharma and Aggarwal ${ }^{13}$, 87 were male $(86.1 \%)$. 
Chronic alcohol consumption accounted $120(80 \%)$ of total cases followed by chronic hepatitis B and C. Our study detected $73.4 \%$ of cirrhotics (110 out of 150) had gastro-esophageal varices at presentation. Twenty eight patients (18.7\%) had low-grade and 82 patients $(54.7 \%)$ had high-grade varices. Mandal et al. ${ }^{12}$ reported that $75.6 \%$ of cirrhotic had varices.

Majority of cases with varices were of Class C. No association was observed between CTP classes and variceal grading.

Average PVD of patients without gastroesophageal varices was $10.800 \pm 1.1402$ $\mathrm{mm}$, while it was $13.731 \pm 1.061 \mathrm{~mm}$ in patients with varices. Patients with small varices had $12.650 \pm 0.7471 \mathrm{~mm}$ and those with large varices had $14.100 \pm$ 0.8883.This difference was statistically significant $(\mathrm{p}<0.01)$. An existence of strong correlation was found between portal vein diameter and the grades of esophageal varices.

In the Indian study by Mandal et al. ${ }^{12}$, average PVD of patients without gastroesophageal varices was $11.545 \pm 1.514$ $\mathrm{mm}(\mathrm{p}<0.05)$ and with varices was 13.998 $\pm 1.123 \mathrm{~mm}$. $\mathrm{Ng}$ et $\mathrm{al},{ }^{14}$ found a mean PVD of $10.5 \pm 2.6 \mathrm{~mm}$ among patients without esophageal varices and mean PVD of $11.5 \pm 2.4 \mathrm{~mm}$ among patients with varices. The average PVD was 11.78 $\pm 1.58 \mathrm{~mm}$ in non-variceal group and $14.05 \pm 2.26 \mathrm{~mm}$ in variceal group $(\mathrm{p}$ $<0.01$ ) by Shanker et al. ${ }^{15}$

The best cutoff of PVD for prediction of esophageal varices for our study population was $>12.25 \mathrm{~mm}$ (Sensitivity $=$ $92.72 \%$, Specificity $=90 \%$ ). Shanker et al. ${ }^{15}$, in India, reported PVD > $12.20 \mathrm{~mm}$, value similar to ours, as a predictor of esophageal varices with sensitivity of 80 $\%$, and specificity of $80 \%$.

Cherian et al. ${ }^{16}$, and Prihatini et al. ${ }^{5}$, found PVD of $13 \mathrm{~mm}$ and $15 \mathrm{~mm}$ respectively to be predictive for variceal detection in cirrhotic patients. Schepis et al. ${ }^{17}$, have proposed that PVD $>13 \mathrm{~mm}$ was an independent risk factor for the presence of varices. Portal vein diameter for development of gastro-esophageal varices was $13.5 \mathrm{~mm}$ according to Thomopoulos et al. ${ }^{18}$ and $11 \mathrm{~mm}$ according to Sarwar et al. ${ }^{19}$

Patients without varices had average spleen size of $12.67 \pm 2.35 \mathrm{~cm}$ and those with varices had $15.367 \pm 1.210 \mathrm{~cm}$. Patients with small varices had $14.98 \pm 1.55 \mathrm{~cm}$ and those with large varices had $15.50 \pm 1.04 \mathrm{~cm}$. This difference was statistically significant $(\mathrm{p}<$ 0.001 ).

Shanker et al. ${ }^{15}$ reported higher average spleen size in variceal group $(14.69 \pm 1.08$ $\mathrm{cm})$ than those in non variceal group $(12.45 \pm 0.65 \mathrm{~cm}) ; \mathrm{p}<0.01$.

Chalasani et al. ${ }^{20}$ described spleen size as an independent factor determining risk of varices.

Thomopoulos et al. ${ }^{18}$ showed that spleen size more than $13.5 \mathrm{~cm}$, values almost similar to ours was associated with gastro-esophageal varices. These findings are consistent to the splenic size of $>13.15$ $\mathrm{cm}$ and $>13.13 \mathrm{~cm}$ in their studies by Serag et al. $^{21}$ and Mandal et al. ${ }^{12}$ respectively. There was $94.5 \%$ sensitivity and $75 \%$ specificity for prediction for presence of esophageal varices when the cutoff value (by ROC curve analysis) of spleen size for was $>13.9 \mathrm{~cm}$. For cutoff 
value of spleen size $>13.5 \mathrm{~cm}$, Shanker et al. ${ }^{15}$ reported $90 \%$ sensitivity and $80 \%$ specificity for prediction for presence of esophageal varices which is in consistency with our results.

Our study showed that there is a correlation between portal vein diameter and the grades of esophageal varices. Cirrhotic subjects with varices had statistically significant greater spleen size than those with no varices. However our study failed to demonstrate correlation between spleen size and grading of varices. In the present study, Pearson correlation between portal vein diameter and spleen size showed that they had significant positive association (correlation coefficient $r=0.52 ; p<0.001)$.

Positive correlation between PVD and grades of esophageal varices and also between spleen size and variceal grading were described by Shankar et al. ${ }^{15}$ Further, Mandal et al. ${ }^{12}$, and Nemichandra et al. ${ }^{22}$ in their studies described direct correlation between portal vein diameter and spleen size. These studies are consistent to our study.

\section{CONCLUSION}

In cirrhotic patients with portal hypertension,

1. As portal vein diameter increases by $>$ $12.25 \mathrm{~mm}$, there is increased risk of development of gastro-esophageal varices; grades of varices increase with increment of portal vein size.

2. As size of spleen increases by $>13.9$ $\mathrm{cm}$, increased risk of development of varices exist.

Hence measurement of portal vein diameter and spleen size by ultrasonography can be recommended as a non invasive predictor for gastroesophageal varices in cirrhosis of liver. Ultrasonogarphy role in a country like Nepal could be tremendous not only for diagnosing cirrhosis with portal hypertension cases but also in assessment of varices as well as long-term clinical monitoring and management.

\section{REFERENCES}

1. Heidelbaugh J, Bruderly M. Cirrhosis and Chronic Liver Failure. Diagnosis and Evaluation J Am Fam Physician 2006; 74(5):756-62.

2. Bacon BR. Cirrhosis and its complications. In:, Kasper DL, Fauci AS, Hauser SL, Longo DL, Jameson JL, Loscalzo J, editors. Harrison's principles of internal medicine.19th Ed. New York: Mc Graw Hill; 2012:2058-66.

3. Zwibel WJ. Ultrasound assessment of the hepatic vasculature. In: Zwibel WJ, Pellrrito JS, editors. Introduction to vascular ultrasonography. 5th ed. Philadelphia: Elsevier; 2005:585-609.

4. Stephanie RW, Cynthia EW. The liver. In: Rumack CM, Wilson SR, Charboneau JW, Levine D, editors. Diagnostic ultrasound. 4th Ed. New Delhi: Elsevier Mosby; 2011:100 125. 
5. Prihatini, J, Lesmana LA, Manan C, et al. Detection of esophageal varices in liver cirrhosis using non-invasive parameters. Acta Med Indones. 2005; 37(3):126-131.

6. D’Amico G, Garcia-Tsao G, Pagliaro L. Natural history and prognostic indicators of survival in cirrhosis: a systematic review of 118 studies. J Hepatol. 2006; 44:217-231.

7. Jensen DM. Endoscopic screening for varices in cirrhosis: findings, implications and outcomes. Gastroenterology 2002; 122:1620-30.

8. Devrajani BR, Soomro AA, Attra KM. Variceal Bleeding and its Dependence on Portal Vein Size in Liver Cirrhotic Patients. World journal of medical sciences 2009; 4(1):5053.

9. Senecal B. Sonographic anatomy of the normal spleen, normal anatomic variants, and pitfalls. In: Bruneton JN (Ed): Ultrasonography of the spleen. Berlin, Springer-Verlag, 1988; 11-13.

10. Sherlock S, Dooley J. Diseases of the Liver and Biliary System, $12^{\text {th }}$ ed. London: Blackwell Scientific Publications; 2011:156-162.

11. Koslin DB, Mulligan SA, Berland LL. Duplex assessment of the splanchnic vasculature. Semin Ultrasound CTMR 1992; 13:34-9.

12. Mandal L, Mandal SK, Bandyopdhyay D, et al. Correlation of portal vein diameter and splenic size with gastro-esophageal varices in cirrhosis of liver.JIACM.2011; 12(4):26670.

13. Sharma SK, Aggarwal R. Prediction of large esophageal varices in patients with cirrhosis of the liver using clinical, laboratory and imaging parameters. Journal of Gastroenterology and Hepatology 22(11):1909-15.

14. Ng FH, Wang SY, Loo CK, Lam KM, Lai CW, Cheng CS. Prediction of esophagogastric varices in patients with liver cirrhosis. J Gastroenterol Hepatol 1999; 14(8):785-90.

15. Shanker R, Banerjee S, Anshul et al. A Study of Association of Portal Vein Diameter and Splenic Size with Gastro-Esophageal Varices in Liver Cirrhosis Patients. IOSR Journal of Dental and Medical Sciences.2016; 15(9):125-29.

16. Cherian JV, Deepak N, Ponnusamy RP, et al. Non-invasive predictors of esophageal varices.Saudi J Gastroenetrol. 2011; 17:64-68.

17. Schepis F, Camma C, Niceforo D, et al. Which patients with cirrhosis should undergo endoscopic screening for esophageal varices detection? Hepatol.2001; 33:333-38.

18. Thomopoulos KC, Labropoulo KC, Mimidis KP, et al. Noninvasive predictors of the presence of large esophageal varices in patients with cirrhosis. Dig Liver Dis.2003; 35 (7):473-8.

19. Sarwar S, Khan AA, Alam A, et al. Non-endoscopic prediction of presence of esophageal varices in cirrhosis. J Coll Physicians Surg Pak.2005; 15(9):528-31.

20. Chalasni N, Imperiale TF, Ismail A, et al. Predictors of large esophageal varices in patients with cirrhosis. Am J Gastroenterol 1999; 94:3285- 91.

21. Serag Esmat and Dalia Omran. Study of noninvasive predictors of portal hypertension in liver cirrhotic Egyptian patients. Journal of American Science 2011; 7(1):962-968.

22. Nemichandra, Singh SK, Yadavarao KV, et al. Non Endoscopic Predictors of Esophageal Varices in Patients with Cirrhosis of Liver. IOSR Journal of Dental and Medical Sciences 2015:14(1):65-68. 